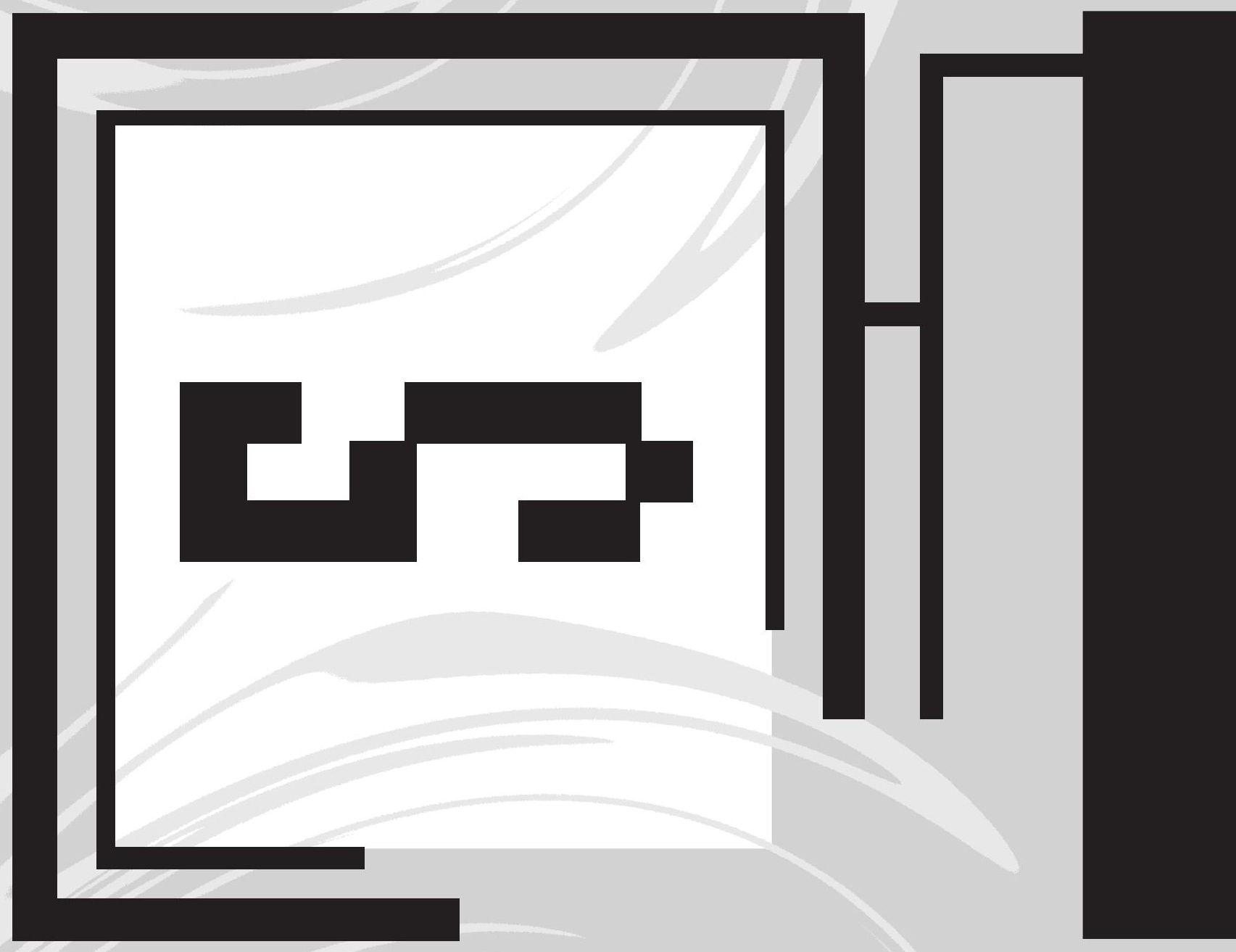




\section{PROJETO SÓCRATES}

\section{UTHF EXPERIÊnCIR DE IIFORIIATIZAÇÃO DO APREEDIZADO nO InSTITUTO DE FÍSICA}

RENATA ZUKANOVICH FUNCHAL

\section{INTRODUÇÃO}

É inegável que estamos vivendo momentos de grande mudança na sociedade promovida pelo advento da informática e de sua rápida popularização. Esse movimento tem grande im- pacto nas formas de pesquisa e ensino na universidade. Uma universidade como a USP, formada por uma comunidade acadêmica dedicada ao desenvolvimento e à transmissão do conhecimento, deve estar na liderança desse processo de informatização. 
Nossa universidade tem criado alguns meios, que muitas vezes ficam restritos à compra de hardware e software, para que o processo de informatização da pesquisa se desenvolva em todas as áreas do conhecimento. No entanto, alguns institutos, como o Instituto de Física, para dar um exemplo que conheço bem, são muito mais informatizados do que a média das unidades da USP. Isso ocorre, a meu ver, por força do tipo de pesquisa que fazemos e também pelo fato de que físicos são treinados a propor e a resolver problemas técnicos, e aprender a usar adequadamente a informática é apenas um problema a mais para nós. Muitos de nós não precisam de treinamento específico para dominar essas novas ferramentas, o que não é verdade para a grande parte dos docentes da USP, especialmente aqueles cuja atuação profissional requer um menor grau de atividade técnica.

No que tange aos esforços da USP para informatizar a graduação, a situação ainda é mais grave, uma vez que muitos de nossos estudantes, mesmo da área de exatas, chegam aqui sem nenhuma familiaridade com os recursos de informática necessários para o seu futuro profissional. A necessidade de treinamento aqui é imperativa.

Há cerca de dez anos a USP criou o Projeto Pró-Aluno, um programa para colocarà disposição dos alunos de graduação da universidade salas com computadores ligados à rede com acesso à Internet para uso acadêmico. Este programa, vinculado à Pró-Reitoria de Graduaçãoe gerenciado tecnicamente pelo CCE, objetivava prover os alunos de graduação das diversas unidades da USP, na capital e no interior, de recursos básicos de informática, tanto do ponto de vista de hardware como de software, para uso exclusivo nas suas atividades acadêmicas. Foram assim criadas diversas salas Pró-Aluno em todos os campi da USP.

Nunca foi e não é objetivo do Projeto Pró-Aluno proporcionar treinamento para a informatização dos estudantes e/ou do corpo docente, nem criar uma infra-estrutura adequada para a informatização do ensino de graduação; etapas estas necessárias para que a informatização do ensino se consolide nesta universidade.
A constatação, por alguns de nossos docentes, da necessidade de um projeto que contemplasse estas duas questões, a do treinamento e a de uma infra-estrutura para o ensino informatizado, levou há três anos ao nascimento do Projeto Sócrates no Instituto de Física da USP (IF-USP).

\section{UM POUCO DA HISTÓRIA DO PROJETO}

Havia no IF-USP, até 1999, uma disparidade entre os recursos básicos de informática oferecidos pelo Pró-Aluno a nossos estudantes de graduação e o nível de informática que nossos alunos precisavam na pós-graduação. Esses recursos há três anos estavam muito aquém das necessidades reais de um profissional na área de exatas, em especial da área de física. Por um lado, ao ingressar da pós-graduação, nossos estudantes tinham que investir por conta própria na sua alfabetização em informática para aprender rapidamente a dominar as linguagens e ferramentas que precisariam utilizar em sua pesquisa. Por outro, aqueles que, uma vez formados, fossem procurar inserção no mercado de trabalho descobririam que não haviam recebido formação adequada em informática fazendo deles profissionais muito pouco competitivos. Tudo isso contrastava com o que acontecia no IF-USP na parte de pesquisa.

Físicos, assim como matemáticos, sempre estiveram próximos da vanguarda do desenvolvimento da computação e da informática. Há muito conhecemos e usufruímos das possibilidades incríveis que a computação oferece para a resolução de nossos problemas, cada vez mais complexos e sofisticados. Não só porque estivemos entre os primeiros a utilizar muitos desses recursos, mas porque fomos, em alguns casos, até inventores dos mesmos, motivados por nossas necessidades particulares. Para exemplificar, citarei algumas das necessidades de nossa comunidade que levaram à criação de alguns desses recursos:

- a necessidade de comunicação rápida e eficiente entre físicos de vários países levou ao desenvolvimento de meios de co- 
municação eficiente e rápida: $e$-mail, $\mathrm{Web}$, videoconferências, etc. O WWW foi criado pelo Centro Europeu de Pesquisas Nucleares (Cern) para facilitar a comunicação entre os pesquisadores do mundo todo que participavam de seus experimentos;

- a necessidade de realizar transferência de dados entre colaboradores de vários países levou ao desenvolvimento de protocolos de transferência e à busca de formatos eficientes de compressão de dados;

- a reconstrução e análise de dados (existem experimentos hoje que registram e digitalizam cerca de 800 mil canais de eletrônica) não só não seria possível sem uma infra-estrutura computacional pesada como também sem um esforço mundial para o desenvolvimento de programas computacionais de reconstrução, análise e simulação do experimento;

- desenvolvimento de uma série de programas/pacotes/bibliotecas específicos para a solução de alguns problemas de física (a Cernlib, por exemplo, existe desde meados dos anos 70);

- desenvolvimento de programas de cálculo algébrico de alta performance, que nos permitem hoje realizar alguns cálculos em algumas horas que levariam anos sem computadores.

Físicos, em geral, tentam resolver problemas novos, cuja solução ainda não é conhecida, e frequientemente são obrigados a inventar métodos novos para isso. Dificilmente um problema que um físico está interessado em resolver já foi resolvido pela Microsoft. Isso de fato não é uma verdade apenas para a física, cada área do conhecimento precisa desenvolver programas especializados para resolver seus próprios problemas. Precisamos desenvolver programas adequados às necessidades e às técnicas particulares das diversas formas de aprendizado.

Por que não estávamos preparando nossos estudantes para essa realidade profissional? Como reverter esta situação de contraste entre a realidade da pesquisa e a do ensino de graduação? Como integrar a formação em informática à formação em física realizada através de nossas aulas expositivas? Essa integração não poderia passar só pela utilização de meios informatizados nos cursos de forma ilustrativa, pela criação de páginas Web para cada disciplina, pela utilização de listas de discussões para cada disciplina, etc., como também pelo treinamento dos professores e alunos na utilização destes e de outros meios disponíveis e a serem criados e pela participação ativa de todos nesse processo.

Surgiu então a idéia, do prof. Jorge L. deLyra, do IF-USP, de criar o Projeto Sócrates, o nome mesmo sugerindo que o aprendizado dessas novas tecnologias se processaria através do "método socrático". Restava definir as bases do projeto. Não foi difícil chegar à conclusão de que o Sócrates deveria ser criado sob a base do sistema operacional Linux.

\section{POR QUE LINUX ?}

Grande parte dos pesquisadores do IFUSP migrou para o sistema Unix há mais de dez anos e para o sistema Linux há cerca de seis. Entre as razões mais importantes que nos levaram à escolha desse sistema operacional estão a confiabilidade do sistema, sua transparência, o fato de ser um sistema com fonte aberta e praticamente gratuito.

A meu ver existem duas razões básicas para usar o sistema operacional Linux também no Projeto Sócrates:

- além de ser um sistema operacional aberto, robusto, gratuito (três qualidades importantes para o uso acadêmico) e de fácil manutenção, ele contém absolutamente todos os recursos necessários para o desenvolvimento de qualquer projeto que necessite de apoio computacional;

- o sistema Linux é extremamente educativo: força o usuário a sair da posição passiva para a ativa (o sistema não toma decisões por você!); permite fazer praticamente tudo que o usuário quer; aguça a curiosidade; não esconde como as coisas são feitas, qualquer um que quiser pode saber exatamente como as coisas funcionam, copiar e modificar programas para o seu uso particular; ajuda a desenvolver o raciocínio lógico; é como um jogo, que nos convida a participar. Em suma, ajuda a moldar o perfil ideal de um profissional 
pensante. Em particular, possibilita desenvolver a nossa capacidade de propor e de resolver problemas de forma independente. Capacidade esta que distingue a formação acadêmica universitária dos outros tipos de formação.

A escolha do sistema operacional do Projeto Sócrates para a informatização da graduação só poderia ser esta. Não apenas por razões econômicas mas sobretudo por razões educacionais!

\section{SÓCRATES COMO INFRA-}

\section{ESTRUTURA COMPUTACIONAL}

O projeto precisava da criação de uma infra-estrutura, tanto do ponto de vista de hardware quanto de software. A criação dessa infra-estrutura seria a primeira etapa do nosso projeto.

Devido a um entendimento com a gerência do Projeto Pró-Aluno no CCE, conseguimos flexibilizar as regras da sala PróAluno do IF-USP, viabilizando utilizar os 28 computadores da sala também para o nosso projeto, que assim pôde usufruir de grande parte dos recursos de hardware proporcionados pelo projeto da USP. Além desses recursos contamos atualmente com duas máquinas: a máquina socrates (1) e a máquina euclides (2).

A arquitetura original da sala Pró-Aluno do IF-USP (SPIF) foi modificada para viabilizar nosso projeto. Criamos na sala uma rede interna fechada que acessa o mundo exterior através do nosso servidor central. Isso faz com que as máquinas da sala sejam invisíveis para o mundo exterior, enquanto este fica transparente para qualquer das máquina da sala. Os 28 micros da sala bootam remotamente do servidor central através da rede, atualmente a $100 \mathrm{Mbps}$, mas esperamos que futuramente a $1 \mathrm{Gbps}$.

A socrates é nosso servidor central, nela estão cadastrados e têm conta todos os usuários do projeto (alunos e professores), nela todos os cadastrados possuem e-mail e página Web, ela serve os discos de usuários via NFS e torna transparente para o mundo exterior as páginas Web dos nossos estudantes (http: //socrates.if.usp.br) e da própria SPIF (http: //proaluno.if.usp.br).

A euclides é a máquina dos professores e dos cursos, nela estão cadastradas as contas das disciplinas. Ela atualmente serve as páginas Web das disciplinas do IF-USP (http://plato.if.usp.br).

Estas duas máquinas estão sendo alimentadas por um no-break que pode manter todo o sistema funcionando por algumas horas no caso de queda de energia elétrica e realizar, no caso de a energia não voltar após um tempo determinado, o shut down do sistema, evitando assim o perigo de dano aos discos e consequiente perda de informação.

Hoje temos mais de 900 alunos cadastrados na socrates. Infelizmente 28 micros não é um número suficiente para atender a todos esses alunos de forma adequada. Para viabilizar o uso cotidiano dos recursos de informática por nossos alunos, no mínimo criar o hábito entre eles de ler e responder $e$-mail e de participar das listas de discussões das disciplinas, calculamos que deveríamos ter um número de micros no mínimo quatro vezes maior que o atual.

É importante enfatizar que a parte técnica de manutenção das máquinas do projeto vem sendo gentilmente gerenciada pelo pessoal técnico em informática do Departamento de Física Matemática, coordenado pelo prof. Jorge L. deLyra, ao qual somos imensamente gratos. Nós não temos infelizmente nenhum técnico em informática vinculado ao nosso projeto.

\section{SÓCRATES COMO PROGRAMA DE TREINAMENTO}

A segunda etapa do projeto, que começou assim que a infra-estrutura mínima foi alcançada, consiste na criação de oportunidades de treinamento. Para isso foi criada no IF-USP uma disciplina de graduação de Introdução ao Linux, com o objetivo de dar apoio computacional aos estudantes ingressantes. Foi também disponibilizado na página Web da SPIF material didático básico sobre Linux e seus aplicativos, inclusive com um manual no estilo de um FAQ. Um grande esforço vem sendo feito no sentido de aprimorar a documentação 
existente. O ideal seria criar um pequeno tutorial, mas infelizmente ainda não tivemos recursos humanos para isso.

Algumas disciplinas, como a de Cálculo Numérico, vêm utilizando esporadicamente a sala para explicar aos estudantes como utilizar na prática alguns recursos computacionais. A necessidade de uma ou mais salas de aula informatizadas é indiscutível, mas ainda não conseguimos recursos para tanto.

Estarão sendo oferecidos, a partir do semestre que vem, cursos-relâmpago semanais na SPIF. Esses cursos, que versarão sobre uma série de tópicos (o sistema Linux, seus aplicativos, editores de texto, HTML, etc.), desde o nível mais básico ao mais avançado, serão ministrados na sua maioria por alunos ou ex-alunos da graduação do IF. Uma experiência nesse sentido foi realizada com grande sucesso no semestre passado.

Acreditamos ser esta etapa a mais difícil e importante de nosso projeto. Infelizmente aqui também contamos apenas com o apoio voluntário de alguns docentes do IF-USP, de alguns alunos e dos monitores da SPIF. Talvez um dos maiores méritos deste projeto seja o fato de que ele vem atraindo a cada dia que passa mais contribuições voluntárias, especialmente por parte dos alunos.

\section{SÓCRATES COMO RECURSO DE INFORMAIIZAÇÃO DAS DISCIPLINAS}

A última etapa do projeto consiste na informatização propriamente dita das disciplinas do IF-USP.

Estamos desenvolvendo, com a ajuda de monitores da graduação, aplicativos para possibilitar a criação automática de páginas Web das disciplinas com um certo formato padrão, contendo algumas informações mínimas, como nome do professor, horário e local das aulas, lista dos alunos matriculados, lista de $e$-mail dos alunos, programa da disciplina, etc. Essas páginas deverão ser alimentadas semestralmente de forma semiautomática por uma base de dados e pelos professores e monitores de cada disciplina.
Estamos criando também um sistema de arquivamento para armazenar a informação das disciplinas semestralmente. Para isso estamos desenvolvendo uma base de dados que deverá ter uma interface de consulta e de alimentação via formulário Web. Esperamos que uma primeira versão deste sistema esteja operando no primeiro semestre de 2003. A descrição do funcionamento do nosso sistema deverá estar disponível para consulta dos professores e monitores dos cursos via página Web.

No momento não dispomos de nenhuma sala de aula informatizada ou de laboratório didático de informática. Estamos no entanto nos preparando para isso. Já somos capazes de digitalizar e transmitir ao vivo os seminários e os colóquios do IF-USP (ver http: //video.if.usp.br). Estamos desenvolvendo alguns programas e aplicativos que poderão ser no futuro igualmente usados para a gravação e transmissão ao vivo de aulas via Web.

Pretendemos também criar um grupo de apoio, formado por alguns monitores selecionados, para ajudar os professores que quiserem informatizar seus cursos. Ofereceremos também minicursos com este objetivo para nosso corpo docente.

Almejamos ainda no futuro a criação de um programa que já demominamos de “Tutorial Cibernético". O objetivo deste programaé proporcionar aos estudantes dos dois primeiros anos um meio de testar seu entendimento de conceitos básicos de física, propondo questões selecionadas de um banco de dados que o estudante deve responder. O programa verificará a resposta do estudante, dando dicas caso sua resposta não esteja correta.

Este é um projeto-piloto ambicioso, mas é um projeto de informatização do ensino no qual realmente acreditamos. Ele contempla não só a disponibilização de uma infra-estrutura de hardware e de software. condição necessária mas não suficiente para o aprendizado, como também a formação de pessoal (discentes e docentes) para a boa utilização dos recursos disponíveis. Achamos que este é o caminho para auxiliar nossos estudantes a se prepararem para enfrentar o desafio de incorporar a informática à sua vida profissional. 